\title{
Splice site selection, rate of splicing, and alternative splicing on nascent transcripts
}

\author{
Ann L. Beyer and Yvonne N. Osheim \\ Department of Microbiology, Molecular Biology Institute and Cancer Center, University of Virginia School of Medicine, \\ Charlottesville, Virginia 22908 USA
}

\begin{abstract}
Based on ultrastructural analysis of actively transcribing genes seen in electron micrographs, we present evidence that pre-mRNA splicing occurs with a reasonable frequency on the nascent transcripts of early Drosophila embryo genes and that splice site selection may generally precede polyadenylation. The details of the process observed are in agreement with results from in vitro splicing systems but differ in the more rapid completion of in vivo splicing. For those introns that are removed cotranscriptionally, a series of events is initiated following 3' splice site synthesis, beginning with ribonucleoprotein (RNP) particle formation at the 3' splice site within $48 \mathrm{sec}$, intron loop formation within $2 \mathrm{~min}$, and splicing within $3 \mathrm{~min}$. The initiation of the process is correlated with $3^{\prime}$ splice site synthesis but is independent of $5^{\prime}$ splice site synthesis, the position of the intron within the transcript, and the age or length of the transcript. In some cases, introns are removed from the $5^{\prime}$ end of a transcript before introns are synthesized at the $3^{\prime}$ end, supporting a possible role for the order of transcription in splice site pairing. In general, our observations are consistent with the 'first-come-first-served' principle of splice site selection, although an observed example of exon skipping indicates that alternative splicing possibilities can be accommodated within this general framework.
\end{abstract}

[Key Words: RNA splicing; ribonucleoprotein particles; alternative splicing; spliceosome; electron microscopy; Drosophila development]

Received February 24, 1988; revised version accepted April 28, 1988.

With the development of in vitro splicing systems, a great deal has been learned about the molecular biochemistry of intron excision from eukaryotic nuclear mRNA precursors (for reviews, see Green 1986; Padgett et al. 1986; Maniatis and Reed 1987). During the first step of splicing, cleavage at the $5^{\prime}$ splice site is coupled to lariat formation within the intron. The lariat is formed by the covalent linkage of the $5^{\prime}$ end of the intron to an A residue at the branch site, located 18-37 nucleotides upstream of the $3^{\prime}$ splice site. In the second step, the two exons are ligated and the intron is released as a lariat. The existence of a bipartite intermediate not only requires that the exons be brought together and accurately positioned, but also held together for ligation. A multicomponent ribonucleoprotein (RNP) complex termed the spliceosome serves this purpose (Brody and Abelson 1985). Conserved sequences at the intron boundaries and branch site function to assemble the spliceosome, through interactions with required factors, which are predominantly the abundant $\mathrm{Sm}$ class of small nuclear ribonucleoproteins (snRNPs) (U1, U2, U5, U4/U6 snRNPs; for review, see Steitz et al. 1987). Spliceosome assembly is a stepwise process involving deposition of proteins and snRNPs at the ends of the intron followed by the stable association of the two ends to form the splicing complex (Frendewey and Keller 1985; Konarska and Sharp 1986; Bindereif and Green 1987; Cheng and Abelson 1987).
There have been many in vivo studies consistent with the above splicing mechanism, including the demonstration of lariat intermediates (Domdey et al. 1984; Rodriguez et al. 1984; Zeitlin and Efstratiadis 1984; Keohavong et al. 1986), participation of U1 snRNPs (Bozzoni et al. 1984; Fradin et al. 1984; Zhuang and Weiner 1986), and association of a factor with the branch site (Patton and Chae 1985). We use an in vivo ultrastructural approach, the Miller chromatin spreading technique, for analysis of the RNP structure of nascent heterogeneous nuclear RNA (hnRNA) transcripts. In these preparations, transcripts occur as smooth RNP fibrils with a width of $\sim 5 \mathrm{~nm}$. Stable RNP particles, $\sim 25 \mathrm{~nm}$ in diameter, interrupt this fibril and occur at nonrandom and specific sites on the transcripts of a given gene (Beyer et al. 1980). In some cases, on more mature transcripts, pairs of nearest neighbor particles become stably associated to form larger particles of $\sim 40 \mathrm{~nm}$, looping out the RNA sequence between them (Beyer et al. 1981). The two 25-nm particles that coalesce can be originally spaced by $\leqslant 100$ nucleotides or as much as $25 \mathrm{~kb}$ of RNA (Beyer 1983; Osheim et al. 1985). In some of the genes exhibiting loop formation, the loops are specifically removed (Beyer et al. 1981) in a process that we believe represents splicing. Direct evidence in support of that is the occurrence of RNP particles specifically at splice junction regions on the three genes that we have been able to identify in chromatin spreads; the $\mathrm{s} 36$ and s 38 
Drosophila chorion genes (Osheim et al. 1985) and the adenovirus major late transcript leader region (A. Beyer, in prep.). On the chorion transcripts, the two $25-\mathrm{nm}$ particles at the splice junctions become stably associated to form a larger $\sim 40$-nm particle while the transcripts are nascent. The smaller and larger particles presumably represent in vivo ultrastructural correlates to spliceosome intermediates and spliceosomes, respectively.

Indirect evidence that we are observing spliceosome formation and splicing comes from the details of the process we observe and their correspondence to results from biochemical studies of splicing in vivo and in vitro. These details, which have either been reported previously (Beyer et al. 1981; Beyer 1983) or will be reported herein, include (1) the frequent observation of the phenomenon; (2) the range in loop length, which is consistent with the known intron length range; $(3)$ the deposition of RNP particles at either end of the segment to be excised but not in between (cf. Black et al. 1985; Ruskin and Green 1985); (4) the importance of the 3' splice region in initiating spliceosome assembly (cf. Frendewey and Keller 1985; Ruskin and Green 1985; Cheng and Abelson 1987; Krämer 1987); (5) the possibility for the coexistence of more than one spliceosome per transcript (cf. Christofori et al. 1987); (6) the preferred but nonobligatory order for intron removal (cf. Zeitlin and Efstratiadis 1984; Hager 1987); and (7) the removal of the bulk of the spliceosome particle with the excised intron (cf. Konarska and Sharp 1987). Other consistent observations are the presence of Sm-snRNPs at transcriptionally active chromosomal sites (Sass and Pederson 1984; Fakan et al. 1986) and the paucity of loop structures on transcripts from heat-shocked Drosophila embryos (Y. Osheim, A. Knight, and A. Beyer, unpubl.|, as splicing is disrupted by heat shock (Yost and Lindquist 1986). The combined evidence is compelling that we are visualizing spliceosome assembly and splicing in vitro. Based on this premise, we are able to discern temporal parameters of the process. Perhaps our most interesting observation is the rapid and cotranscriptional selection of splice sites, in agreement with the first-come-first-served principle of Aebi et al. (1986) and the implications this may have concerning the appropriate pairing of splice sites in vivo.

\section{Results}

The genes analyzed are unidentified transcription units from Drosophila melanogaster early embryos. They are presumed to be polymerase II transcription units, because they clearly differ in morphology from nucleolar genes (Miller and Beatty 1969) and are longer than expected for polymerase III genes. The RNP structures seen are not peculiar to this developmental stage or organism. Similar structures have been seen on a wide variety of polymerase II transcripts, including those from HeLa cells.

For most transcription units visualized, there appear to be discrete initiation and termination sites, and the transcripts increase regularly in length, as expected, from the initiation to the termination end of the gene. In some transcription units, however, including those shown here, some of the transcripts are shorter than expected for their position on the template. In a previous report, we argued that it was unlikely that these transcripts had initiated at an alternative promoter, and we showed that transcript shortening was not random, but, rather, was due to the removal of looped out segments of RNA (Beyer et al. 1981). This and other evidence presented in the introduction indicate that we are visualizing splicing. Although it is difficult to quantitate information from chromatin spreads, we reanalyzed 99 examples of Drosophila embryo polymerase II transcription units that we had available from previous studies unrelated to RNP structure and RNA processing. Eighty-five percent displayed 25-nm RNP particles, $46 \%$ displayed loop formation, and at least $14 \%$ displayed loop removal. Thus, the visualization of loop formation and removal is not an extremely rare event.

The transcription unit analyzed in Figure 1 displays the basic phenomenon. Transcript 28 has an RNP loop (intron) near its $5^{\prime}$ end, with a large loop-base particle (spliceosome). Transcript 27 is much shorter than expected for its position on the template and has apparently been spliced. That is, the length missing on 27 corresponds to the length of the loop on 28 and also to the distance between 25 -nm particles (spliceosome intermediates at $5^{\prime}$ and $3^{\prime}$ splice sites) on transcripts $23-26$. A gene map is shown at the bottom of Figure 1C, illustrating our proposed exon-intron structure for the transcripts of this gene. There may be a second small intron at the position of the second large particle, as indicated. When the introns are short ( $\sim 250$ nucleotides or less), an intron loop cannot be seen in these preparations (Osheim et al. 1985).

It is a general observation, as was shown for the chorion transcripts (Osheim et al. 1985) and as is seen in Figure 1 and subsequent figures, that a $25-\mathrm{nm}$ particle assembles at the putative $3^{\prime}$ splice site very shortly after its synthesis. Because these particles cover a minimum of $\sim 100$ nucleotides (Osheim et al. 1985) and because the branch site and $3^{\prime}$ splice site are within 37 nucleotides of each other (Konarska et al. 1985; Reed and Maniatis 1985; Ruskin et al. 1985), we cannot resolve whether separate factors are deposited at the two sites, as has been shown to occur in vitro (Black et al. 1985; Chabot et al. 1985; Ruskin et al. 1988).

Note from the RNP fibril map (Fig. 1C) that the 25-nm particle does not assemble at the presumed $5^{\prime}$ splice site until the $3^{\prime}$ splice site is synthesized and assembled into an RNP particle (starting with transcript 21). There is, however, an indication that the $5^{\prime}$ splice site is recognized prior to this, perhaps by a smaller or less stable factor, because nine of the less mature transcripts $(1-20)$ display an irregularity (small particle or hairpin looplike structure) near the proposed 5 ' splice site. These first 20 transcripts exist predominantly as $\sim 5$-nm-wide RNP fibrils with little secondary structure, which is the general and primary level of RNP packaging observed in these preparations. Occasionally, additional particles are 


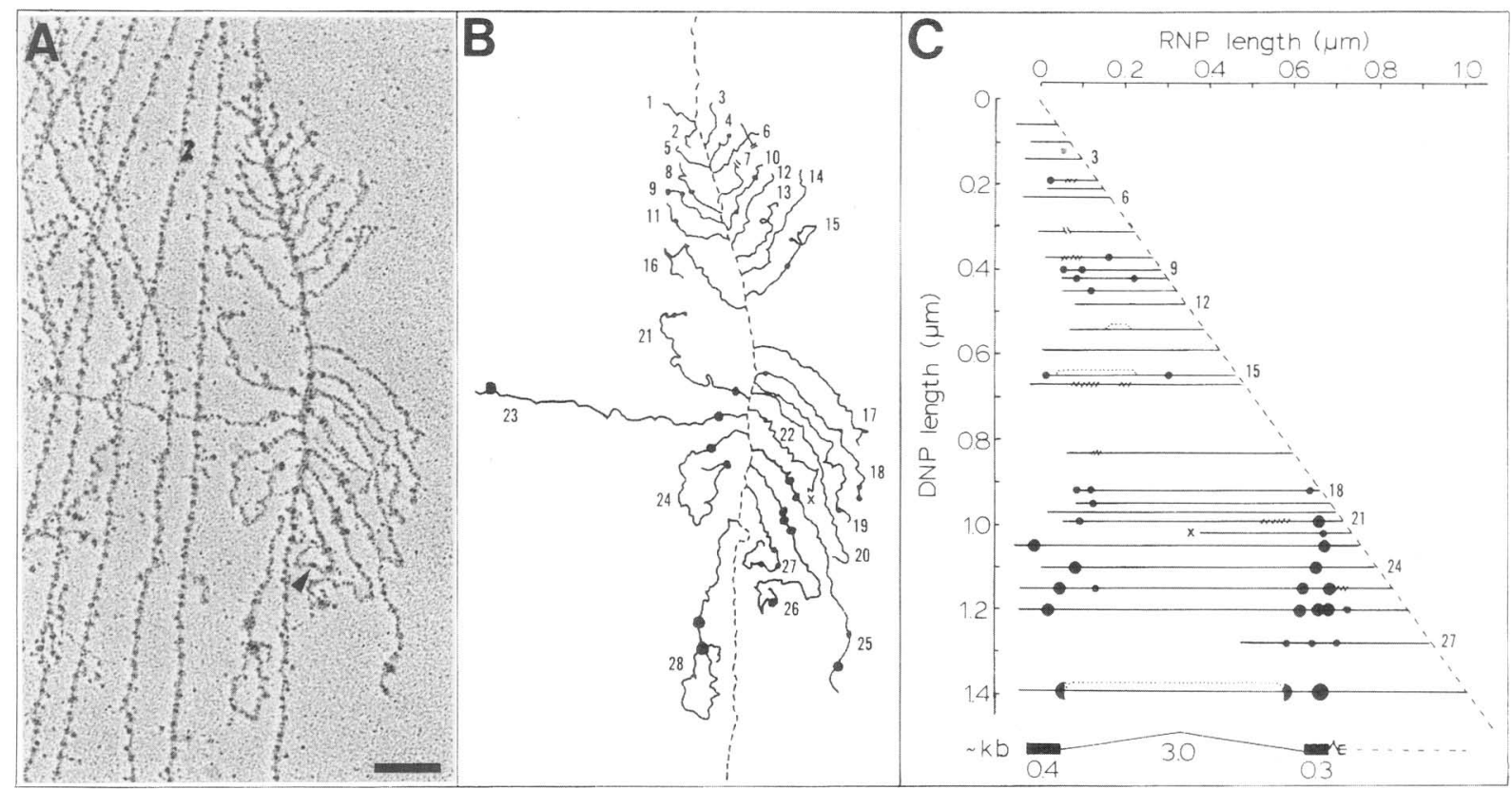

Figure 1. General phenomenon of loop formation and removal. (A) Electron micrograph of a Drosophila embryo transcription unit. Arrowhead indicates possible small particle at site of proposed intron excision. Bar represents $0.2 \mu \mathrm{m}$. $(B)$ Interpretive tracing of micrograph. (- - - ) Template chromatin; $(-)$ RNP fibrils; $(\bullet)$ RNP particles; $(x)$ presumed broken transcript. Transcript numbering starts at initiation end of gene. $(C)$ RNP fibril map. Spacing of the fibrils on the vertical axis corresponds to their position on the chromatin template. Transcripts are shown as straight lines of the appropriate length, with corresponding sequences approximately aligned $\left(5^{\prime}\right.$ termini to the left). This is accomplished by abutting the $3^{\prime}$ termini to the sloped dashed line, which represents the best fit least-squares line of fibril length for the unprocessed and unbroken transcripts, (all except 22 and 27). ( $\bullet$ ) RNP particles of three sizes: small $(\leqslant 20 \mathrm{~nm})$, intermediate $(20-35 \mathrm{~nm})$, and large $(>35 \mathrm{~nm})$; (hatched regions) short lateral projections from the fibrils traced as hairpin loops. The dotted line drawn over the schematic fibrils represents the loop structure and connects points of intramolecular contact. At the bottom is shown the proposed exon-intron structure of the transcripts and approximate lengths in kb (see Methods). (a) Exons; (thin lines) intron; (. . . ) difficult to assign as intron or exon.

seen on the transcripts at positions that do not correspond to presumptive $5^{\prime}$ and $3^{\prime}$ splice sites, as judged by the complete analysis of the gene (e.g., transcripts 7,10 , and 15, Fig. 1). These particles generally occur at different positions on different transcripts, are usually $\leqslant 20$ $\mathrm{nm}$ in diameter, and may represent some remnant of the disrupted higher order RNP structure unrelated to splicing.

A final general observation from Figure 1 is that the bulk of the large $40 \mathrm{~nm}$ particle, which is present at the base of the loop before intron removal, is lost from the nascent transcript upon splicing. That is, transcript 27 displays only a very small particle (arrowhead in Fig. 1A) in the region of proposed intron excision.

As shown in Figure 1, the assembly of a 25-nm particle at the 5' splice site did not occur until the synthesis of the $3^{\prime}$ splice site. Figure 2 demonstrates the same phenomenon on introns of different lengths, indicating that RNP particle assembly correlates with transcription of the $3^{\prime}$ splice site and not with the age or length of the transcript. In Figure 2A-C, the $3^{\prime}$ splice site particle for the large intron first appears on transcript 4 . The three previous transcripts, although quite long, lack 25-nm $5^{\prime}$ splice site particles (but do exhibit some irregularities in the region), whereas the three subsequent transcripts have either a $5^{\prime}$ splice site particle or a looped intron plus spliceosome. In Figure 2D-F, the transcripts have at least two, and possibly three, introns. The first two introns are rather short and approximately the same length $(\sim 0.9 \mathrm{~kb})$. Both demonstrate the rapid assembly of spliceosome intermediates at both junctions shortly after synthesis of the $3^{\prime}$ splice site, just as the longer introns in Figure $1(\sim 3 \mathrm{~kb})$ and Figure $2 \mathrm{~A}(\sim 7.6 \mathrm{~kb})$ did. The two RNP fibril maps in Figures $2 \mathrm{C}$ and $\mathrm{F}$ have been drawn to the same scale to emphasize the difference in intron lengths.

In Figure 3, we have plotted the first occurrence of the 3' splice site RNP particle, 5' splice site RNP particle, loop formation, and loop removal as a function of distance traversed on the template from the site of synthesis of either the $5^{\prime}$ or $3^{\prime}$ splice site. The sample includes 14 introns occurring on 8 genes; the introns range in length between 0.14 and $1.79 \mu \mathrm{m}$ (or $\sim 0.6-8 \mathrm{~kb}$ ). Nine of these introns occur on the genes in Figures 1, 2, 5 , and 6, and the rest on genes not shown. There is an excellent correlation between each each of the four phenomena and synthesis of the $3^{\prime}$ splice site, with correlation coefficients $(\mathrm{r})$ greater than 0.9 (Fig. $3 \mathrm{E}-\mathrm{H}$ ), and a much poorer correlation with the synthesis of the $5^{\prime}$ splice site ( $\mathrm{r}$ between 0.59 and 0.75 ) (Fig. 3A-D). The assembly of the structures we visualize follows shortly after the synthesis of the $3^{\prime}$ splice site. The time of as- 
sembly is not obviously influenced by the synthesis of the $5^{\prime}$ splice site, the age or length of the transcript, or the position of the intron within the transcript. The $y$ intercepts of the best fit lines for the four graphs on the right (Fig. 3E-H) represent the typical distance in micrometers traversed on the DNA template between 3' splice site synthesis and the first occurrence of the phenomenon on a nascent transcript. Table 1 lists these intercepts and shows that $3^{\prime}$ splice site particle formation precedes $5^{\prime}$ splice site particle formation, which precedes intron looping, which precedes splicing. If the distances in micrometers are converted to time after synthesis of the $3^{\prime}$ splice site, it is found that the first particle is deposited within $48 \mathrm{sec}$ and splicing is complete within $3 \mathrm{~min}$. These should be considered maximum values because the maximum DNA compaction was assumed in converting these average distances from micrometers to kilobase pairs $(4.8 \mathrm{~kb} / \mu \mathrm{m}$; see Methods) and because our approach, which records the first occurrence of the phenomenon on a transcript, is limited by the number of transcripts on these less than fully transcribed genes. The chorion genes analyzed previously are maximally loaded with RNA polymerases (Osheim et al. 1985). On the $s 38$ chorion genes, the first $25-\mathrm{nm}$ particle at the $3^{\prime}$ splice region is formed on average at $\sim 0.1 \mu \mathrm{m}$, and the first 40-nm particle /the equivalent of loop formation) at $\sim 0.42 \mu \mathrm{m}$ after synthesis of the $3^{\prime}$ splice site. These values convert to 13 and $55 \mathrm{sec}$ after $3^{\prime}$ splice site synthesis, respectively, (using the appropriate conversion factor of $3.3 \mathrm{~kb} / \mu \mathrm{m}$; Osheim et al. 1986) and are
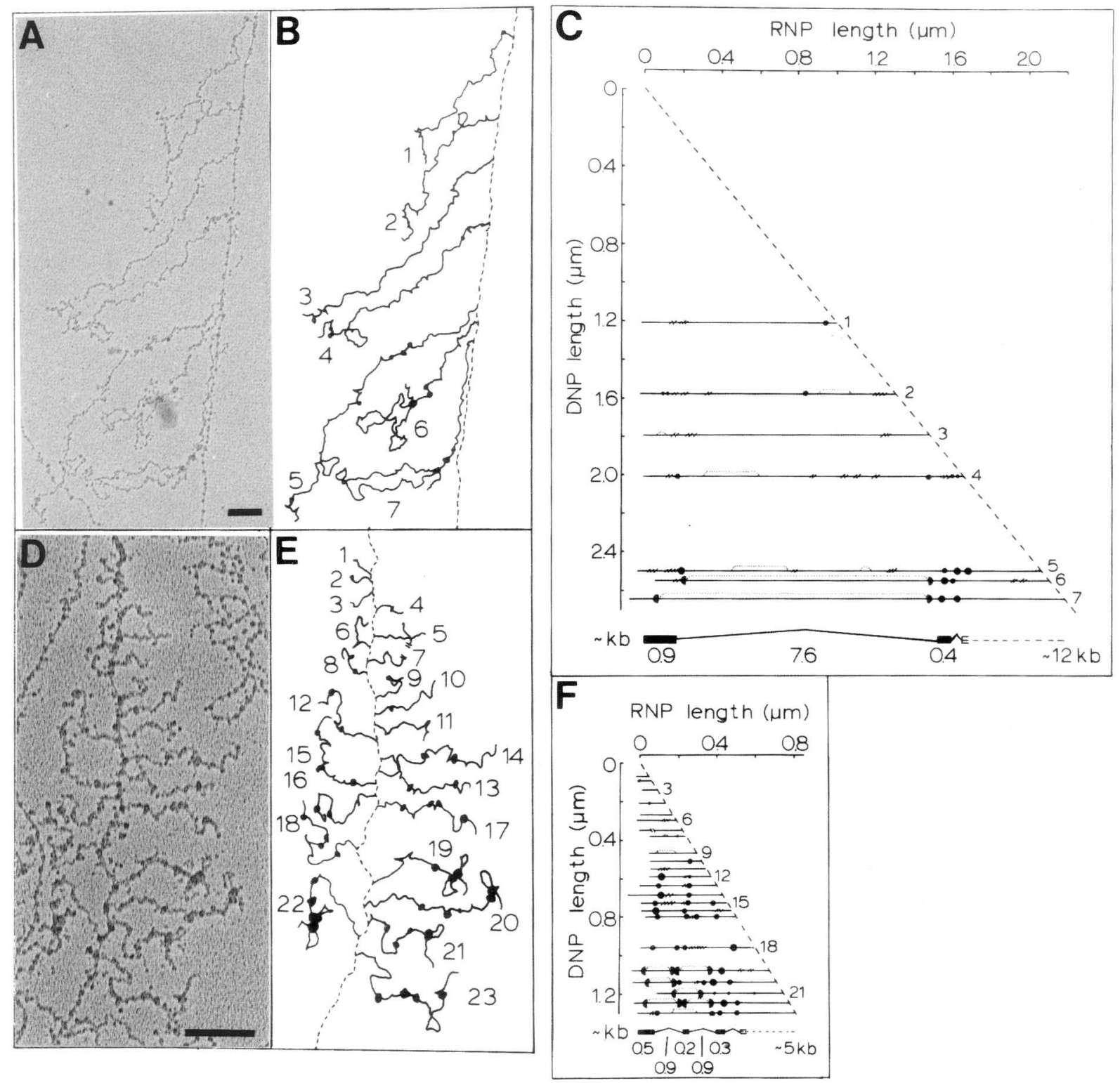

Figure 2. RNP particle deposition at splice junction regions follows $3^{\prime}$ splice site synthesis for both long and short introns. $(A, D)$ Electron micrographs of two different Drosophila embryo transcription units. Bars represent $0.2 \mu \mathrm{m}$. $(B, E)$ Interpretive tracing of EMs in $A$ and $D$, respectively. $(C, F)$ RNP fibril maps, drawn to the same scale, for the transcription units in $A$ and $D$, respectively. For additional details of RNP fibril maps, see Figure 1. 


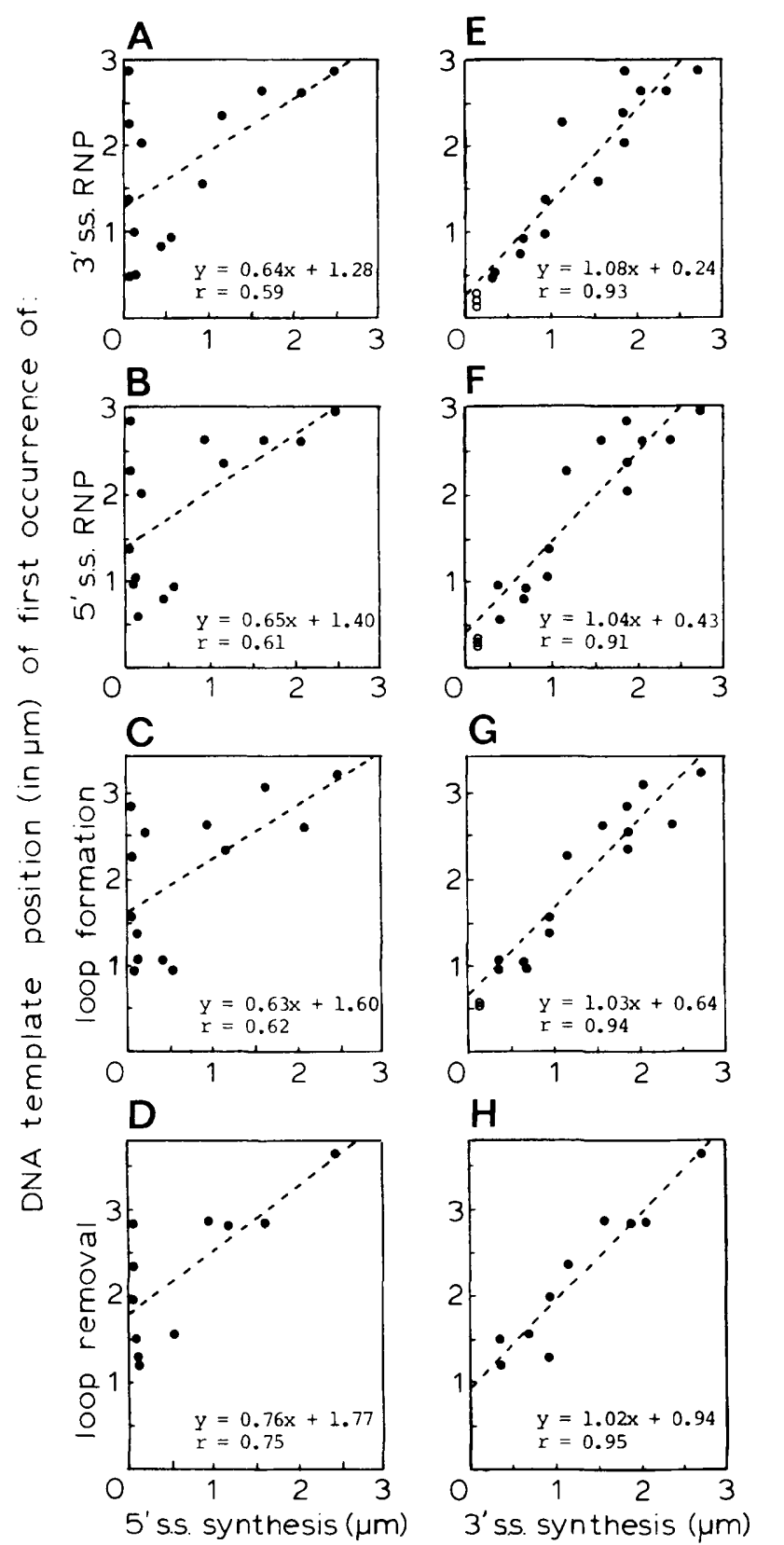

Figure 3. Correlation between splicing-associated phenomena and synthesis of the $3^{\prime}$ splice site. Each graph plots a series of points $(\bullet)$ in which $\mathrm{x}=$ the distance on the template in $\mu \mathrm{m}$ from the extrapolated initiation site to the extrapolated point of synthesis of either the $5^{\prime}(A-D)$ or $3^{\prime}(E-H)$ splice site, and $y=$ the template position (in $\mu \mathrm{m}$ measuring from the extrapolated initiation site) of the transcript displaying the first occurrence of the four phenomena: $(A, E) 3^{\prime}$ splice site RNP particle; $(B, F) 5^{\prime}$ splice site RNP particle; $(C, G)$ loop formation; $(D, H)$ loop removal, or splicing. The equations for the best fit linear regression lines are shown for each graph, as well as the correlation coefficients $(\mathrm{r})$. The intron sample size and composition are described in the text. The open circles in $E-G$ represent the appropriate points for three $\mathrm{s} 38$ chorion introns, which were not included in the linear regression analyses. probably at the lower end of the time range for splicing complex formation that we are able to resolve. (The chorion data are included in Fig. 3E-G as open circles but were not used to derive the least-squares equations.) Assuming an elongation rate of 1500 nucleotides per min at $25^{\circ} \mathrm{C}$ (Kafatos 1972; Mann 1986), the $1950 \mathrm{nu}-$ cleotide s38 transcripts finish transcription after $\sim 80$ sec, or $64 \mathrm{sec}$ after $3^{\prime}$ splice site synthesis. We only rarely see the $40-\mathrm{nm}$ particle removed from the nascent chorion transcripts and thus suspect that the final splicing of these transcripts typically occurs after $64 \mathrm{sec}$, which would be entirely consistent with the results in Table 1.

Our chromatin spreading conditions have hypotonically disrupted cells and the native structure of the RNP. Based on the dependence of 5 ' splice site particle formation on $3^{\prime}$ splice site synthesis, it is probable that the two sites are in contact in vivo, but still separable by chromatin dispersal conditions, perhaps because they are not yet linked covalently by branch formation. If we prepare our spreads at $\mathrm{pH} 7.5-8$ instead of $\mathrm{pH} 9$, we still observe chromatin dispersal, but the RNA transcripts appear as compact RNP granules of $50-60 \mathrm{~nm}$, closely associated with the deoxyribonucleoprotein (DNP) template, as shown in Figure 4. This structure is reminiscent of the native configuration of Chironomus BR2 transcripts (Skoglund et al. 1983) and is undoubtedly more representative of the native structure of nascent RNA than the dispersed fibril seen in a typical Miller spread. Such a configuration, in which the entire length of a transcript is contained within a small area, yet in a predominantly single-stranded form due to the primary RNP packaging, might allow the rapid scanning of intramolecular sequences for cognate splice junctions and would discourage intermolecular splicing.

Our observation that splice site selection and splicing can occur on nascent transcripts within minutes of transcription suggests that the $5^{\prime}$-most introns may be com-

Table 1. First occurrence of splicing-associated events on nascent transcripts

\begin{tabular}{|c|c|c|c|c|}
\hline \multirow{3}{*}{$\begin{array}{l}\text { Ultrastructural } \\
\text { phenomenon }\end{array}$} & \multirow{2}{*}{\multicolumn{2}{|c|}{$\begin{array}{l}\text { Distance after } \\
3^{\prime} \text { splice } \\
\text { site synthesis }\end{array}$}} & \multicolumn{2}{|c|}{$\begin{array}{c}\text { Time (sec) after } \\
3^{\prime} \text { ' splice } \\
\text { site synthesis }\end{array}$} \\
\hline & & & \multirow{2}{*}{$\begin{array}{c}\text { high } \\
\text { estimate }^{\mathrm{c}}\end{array}$} & \multirow{2}{*}{$\begin{array}{c}\text { low } \\
\text { estimate }\end{array}$} \\
\hline & $\mu \mathrm{m}^{\mathrm{a}}$ & $\mathrm{kb}^{\mathrm{b}}$ & & \\
\hline $3^{\prime}$ splice site RNP & 0.24 & 1.2 & 48 & 13 \\
\hline 5' splice site RNP & 0.43 & 2.1 & 84 & 25 \\
\hline Loop formation & 0.64 & 3.1 & 124 & 55 \\
\hline Loop removal & 0.94 & 4.5 & 180 & not seen \\
\hline
\end{tabular}

a Values from Fig. $3 \mathrm{E}-\mathrm{H}$ ( $y$ intercepts).

b Assume $4.8 \mathrm{~kb} / \mu \mathrm{m}$ (maximum compaction).

c Values obtained by converting the maximum $\mathrm{kb}$ values in the previous column to seconds, assuming a transcription elongation rate of 1500 nucleotides per min at $25^{\circ} \mathrm{C}$ (Kafatos 1972; Mann 1986).

d Values obtained for three s38 chorion genes, using the known compaction ratio of $3.3 \mathrm{~kb} / \mu \mathrm{m}$ (Osheim et al. 1985, 1986) and assuming an elongation rate of 1500 nucleotides per min at $25^{\circ} \mathrm{C}$. 


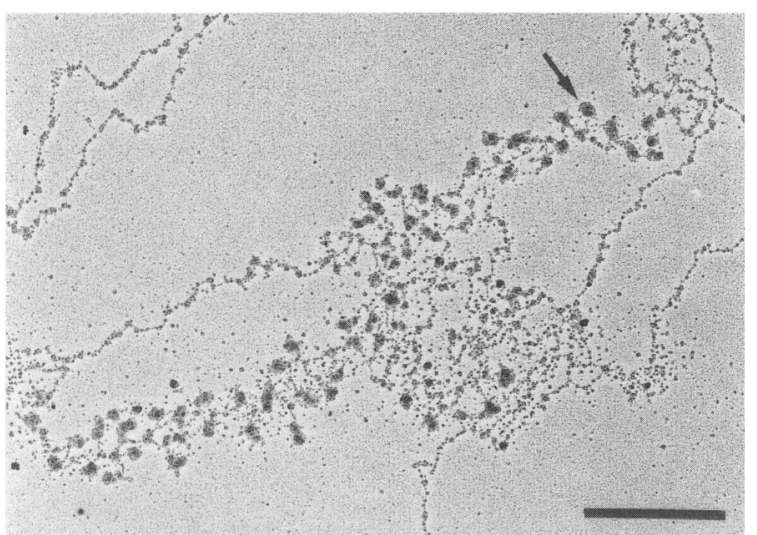

Figure 4. Chromatin spreads at near neutral pH show RNA transcripts as compact RNP granules of $\sim 60 \mathrm{~nm}$. EM from a chromatin spread with a $\mathrm{pH}$ of $\sim 7.7$, showing several DNA strands and two transcription units, obvious as arrays of large RNP granules $(\rightarrow)$ closely associated with the template. Bar represents $0.5 \mu \mathrm{m}$.

mitted to splicing, or spliced, before downstream introns are synthesized. We do, indeed, observe this phenomenon, which indicates that the order of transcription might be a factor in the orderly pairing of appropriate splice junctions in a long transcript (cf. Aebi et al. 1986). The micrograph in Figure 5 shows two copies of the same gene on newly replicated sister chro- matids. Such paired genes are seen frequently when the chromatin of early cellular blastoderm Drosophila embryos is prepared for electron microscope (EM) visualization (McKnight and Miller 1979). The RNP fibril maps for the two gene copies have been combined on the same graph (Fig. 5C), which serves to show their identical processing patterns. These genes are relatively long, measuring $4 \mu \mathrm{m}$, or $\sim 19 \mathrm{~kb}$, and have at least five introns, as shown on the proposed transcript map (Fig. 5C). The plateau shape of the graph of RNP fibril length vs DNP position (Fig. 5C, inset) is due to the observation that RNA sequences are being spliced at the $5^{\prime}$ end as fast as they are being synthesized at the $3^{\prime}$ end. Transcripts 5 and 7 have excised intron 1 prior to synthesis of introns 4 and/or 5. The splicing proceeds generally, but probably not obligatorily, in a $5^{\prime} \rightarrow 3^{\prime}$ direction. (e.g., based on loop size, transcript 8 has apparently lost intron 3 prior to intron 2). Splicing complex formation and splicing are occurring at the same rate on these transcripts as on other transcripts reported in this paper, but splicing activity appears greater due to the length of the genes and the large number of ultrastructurally distinguishable introns.

Another pair of sister chromatid transcription units, shown in Figure 6, displays an apparent example of alternative splicing, specifically exon skipping. The $\sim 4.9-$ $\mathrm{kb}$ loop (transcript $1^{\prime}$ ) and the $\sim 2.9-\mathrm{kb}$ loops (transcripts 4 and $\left.3^{\prime}\right)$ flank a small exon, which occurs in the middle of the long intron loop in transcript $4^{\prime}$. Interestingly, in

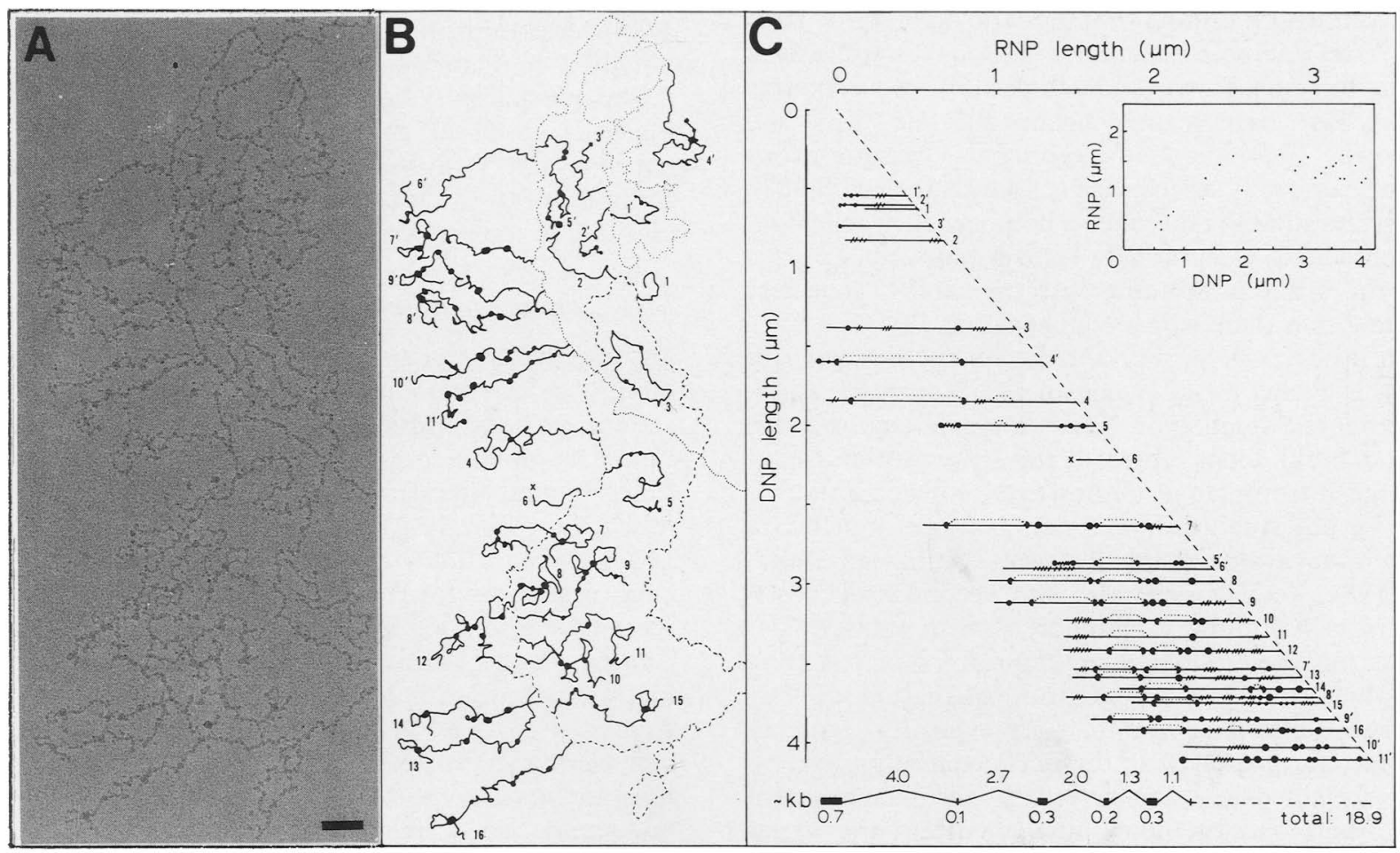

Figure 5. Pair of transcription units displaying five cotranscriptionally spliced introns. $(A)$ Electron micrograph of $D r o s o p h i l a$ embryo sister chromatid transcription units. Bar represents $0.2 \mu \mathrm{m}$. (B) Interpretive tracing of EM. One DNA strand is shown as a dashed line and the other as a dotted line. (C) RNP fibril map displaying transcripts from both gene copies. Inset graph shows RNP fibril length as a function of DNP template position. For additional details of RNP fibril maps, see Figure 1. 
transcript $4^{\prime}$, where the second exon is being skipped by the splicing process, it is not marked by any RNP particles (arrow in Fig. 6A). Thus, there is no violation of the 'no particles within loops' rule (Beyer et al. 1981), even at presumptive splice junction sites, consistent with the notion that the $25-\mathrm{nm}$ particles represent a commitment to splicing. (Although we cannot determine the $5^{\prime} \rightarrow 3^{\prime}$ direction of the RNA within the loop, measuring in either direction from the loop base reveals no unusual ultrastructure at the sites that are particulate on neighboring transcripts. This does not, however, rule out the possible presence of a trans-acting protein factor at the skipped junctions, whose presence may prevent snRNP binding.)

For the genes in Figure 5, we discussed how the order of splice site synthesis may influence splicing options. Clearly, the strictest interpretation of such a model is inappropriate, as has been shown previously by several biochemical studies of splicing in vivo (e.g., Mitchell et al. 1986) and as is shown for transcript $4^{\prime}$ in Figure 6. It is worth nothing, however, that on five of the six transcripts for which the splicing choice can be discerned $\left(1^{\prime}-4^{\prime}, 4,5\right)$, the first-come-first-served rule is obeyed. The pattern in Figure 6, in fact, can be interpreted to be that the small exon is skipped only when the first intron is still present on the nascent transcript and that the critical choice is whether or not the first $3^{\prime}$ splice site (at the end of the $\sim 4.9 \mathrm{~kb}$ intron) is 'selected' by the splicing machinery (cf. Falkenthal et al. 1985; Bernstein et al. 1986).

We do not know the identity of the gene pair in Figure 6 and cannot determine whether the splicing of transcript 4 represents a productive alternative splice or a splicing mistake. However, such patterns of alternative splicing have been seen biochemically (e.g., King and Piatigorsky 1984) and are categorized as cassette exons that are regulated stochastically (Breitbart et al. 1987). Our results suggest that when a homogeneous cell population produces alternatively spliced transcripts from a gene, the different splicing patterns can be transcript specific rather than gene or cell specific.

Two other explanations for the observed transcript pattern in Figure 6 can be considered. First is the possibility that the small exon 2 does not exist and that the 4.9- and 2.9-kb loops represent the stepwise removal of the large intron. There is, however, considerable evidence for one-step intron excision and against stepwise intron removal (for discussion, see Zeitlin and Efstratiadis 1984; Keohavong et al. 1986). Second is the possibility of two alternative promoters, with transcript $1^{\prime}$ representing use of the first and transcript 4 representing use of the second. We consider this explanation unlikely because alternative promoters are typically tissue or stage specific and because the entire transcript pattern can be explained very satisfactorily by the phenomena of loop formation and removal, just as on the other genes reported in this paper. Even if two promoters are being used on the genes in Figure 6, transcripts $1^{\prime}$ and $4^{\prime}$ still display alternative splicing of transcripts from the same promoter (i.e., use of two $3^{\prime}$ splice sites for the same $5^{\prime}$ splice site), and our conclusions regarding the function of $25-\mathrm{nm}$ particles remain the same.

\section{Discussion}

\section{Visualization of splicing in vivo}

In this paper, we deduce kinetic and structural parameters of the in vivo splicing process, based on the assumption that the ultrastructure observed represents splicing on unidentified transcripts. The assumption is supported by the occurrence of the same ultrastructure specifically at splice sites on Drosophila chorion genes (Osheim et al. 1985), by the details of the process, and by additional indirect evidence discussed in the introduction.

In a previous report on the phenomenon of loop removal, we referred to the process as cleavage of nascent transcripts but discussed that it was difficult to distinguish between cleavage and splicing (Beyer et al. 1981). The RNA loops that are most amenable to analysis are large and occur near the 5 ' ends of the transcripts. When loop removal occurs, it is difficult to determine whether the relatively short $5^{\prime}$ exons are spliced onto the remaining transcript or cleaved off with the loop, especially given the differences in RNP compaction between different transcripts. The genes reported in this paper have short but distinguishable $5^{\prime}$ exons. Length measurements are more consistent with their retention on the nascent transcripts rather than with their removal with the loops (Fig. 1, 2F, 5, 6). In addition, in Figures 5 and 6 , the $5^{\prime}$ tails tend to lengthen as loops are removed, as expected from the splicing of additional small exons. Finally, two unambiguous examples of internal loop removal preceding $5^{\prime}$ terminal loop removal have been mapped on insect genes (Hager 1987; A. Beyer, M. Jamrich, and Y. Osheim, in prep.) (possibly also transcript 8 in Fig. 51, clearly indicating splicing rather than cleavage of transcripts.

\section{RNP structure of nascent polymerase II transcripts}

EM visualization of dispersed chromatin yields a simple picture of the RNP packaging of polymerase II transcripts: a rather uniform linear RNP fibril that is interrupted at nonrandom positions with larger RNP particles. In vivo, this structure is presumably wound into a much more compact structure (Fig. 4; Skoglund et al. 1983), which allows the rapid scanning of intramolecular sequences for cognate splice junctions. The proteins responsible for the fibrillar RNP structure are deposited on the RNA at the DNA-RNA transcription fork and are presumably responsible for stabilizing and condensing the RNA and suppressing intramolecular base-pairing (cf. Solnick and Lee 1987). We suspect that the proteins responsible are the core hnRNP proteins (for review, see Chung and Wooley 1986), which are known to bind stoichiometrically (Lothstein et al. 1985) and without sequence specificity to hnRNA (Pullman and Martin 1983; Wilk et al. 1983). In addition, the basic hnRNPs are present on nascent transcripts (Fakan et al. 

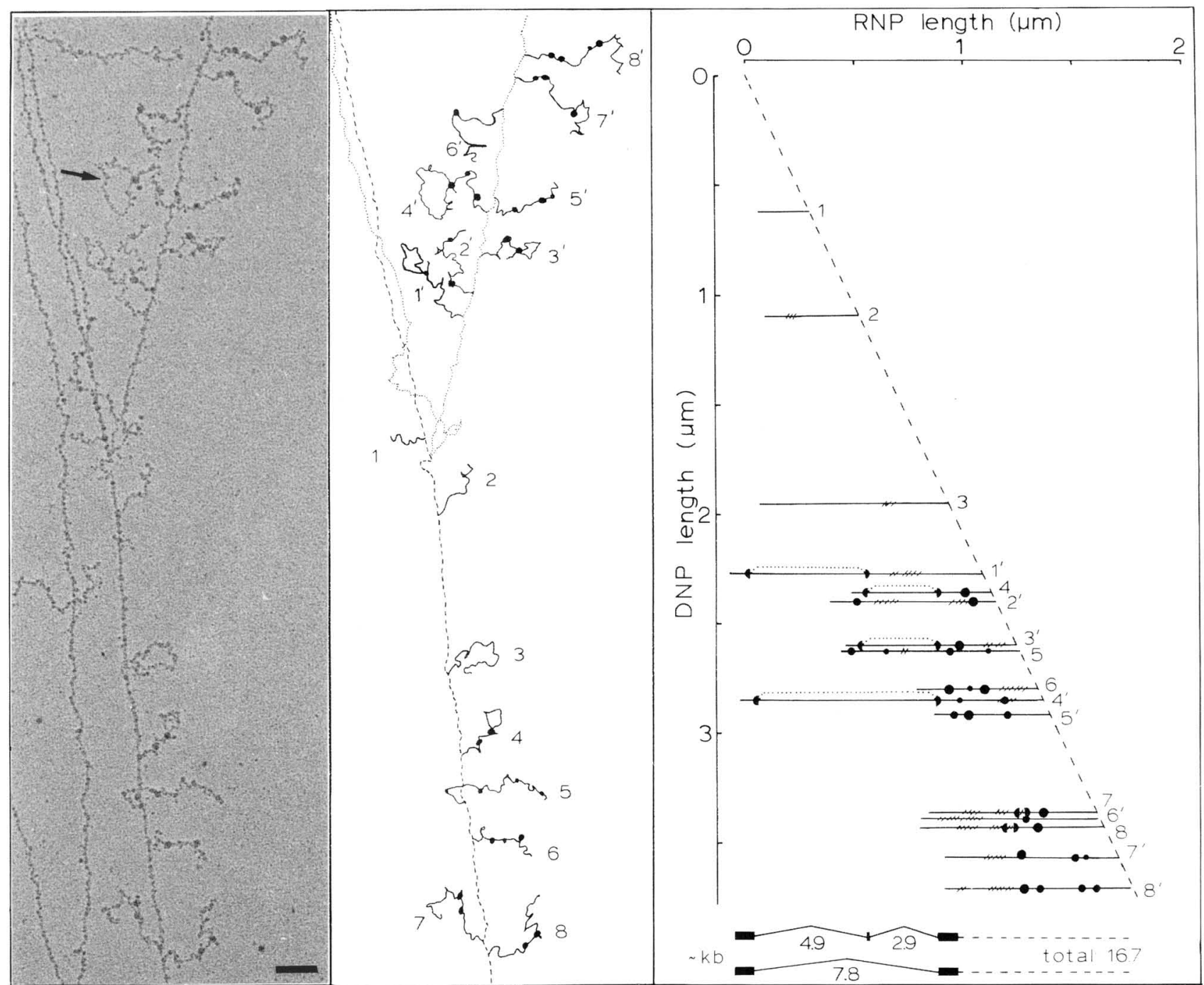

Figure 6. Pair of transcription units displaying alternative splicing. $(A)$ Electron micrograph of Drosophila embryo sister chromatid transcription units. $(\rightarrow)$ The intron loop on transcript $4^{\prime}$ that presumably includes a small exon. Bar represents $0.2 \mu \mathrm{m}$. $(B)$ Interpretive tracing of EM. One DNA strand is shown as a dashed line and the other as a dotted line. $(C)$ RNP fibril map displaying transcripts from both gene copies. The two proposed splicing patterns are shown at the bottom. For additional details of RNP fibril maps, see Figure 1 .

1986), have helix-destabilizing properties (Thomas et al. 1981; Cobianchi et al. 1986; Kumar et al. 1986; Lahiri and Thomas 1986; Riva et al. 1986), and form fibrillar structures on RNA under certain conditions (Nowak et al. 1980; Conway et al. 1988). In the particulate form of hnRNP, 700 nucleotides of RNA are packaged per particle (Conway et al. 1988), as opposed to the 100-150 nucleotides in the $25-\mathrm{nm}$ splice junction particles. In previous reports (Beyer et al. 1980, 1981), we proposed that the $25-\mathrm{nm}$ particles on nascent transcripts were a subset of particularly stable hnRNP particles because of their similarity in size to isolated hnRNP particles (Beyer et al. 1977) and because they were larger than the single snRNPs ( $\sim 12 \mathrm{~nm}$ diameter; Spector et al. 1983), which were known at that time to be present at splice junction sequences (Osheim et al. 1985). With the knowledge of additional snRNP involvement in the splicing complex (Grabowski and Sharp 1986) and compelling evidence that the particles occur at splice junc- tion sequences (at least in those cases where loops eventually form), we now suspect that the stable $25-\mathrm{nm}$ particles are spliceosome intermediates consisting primarily of snRNPs and other required splicing factors. A reasonable interpretation of the ultrastructure is that hnRNPs are present in these particles inasmuch as they coat the entire length of the transcript, serving as the 'scaffold' (Steitz et al. 1987) or 'operating table' (Dreyfuss 1986) for splicing, but it is not necessary to invoke their additional presence based on particle size. Their critical role in the splicing process (Choi et al. 1986; Sierakowska et al. 1986) may thus be structural, although a more specific role for individual hnRNP proteins is quite possible. Clearly, higher resolution approaches such as immuno-EM are required to address the presence of specific hnRNPs, as well as snRNPs, in the particulate and fibrillar regions. It is possible that we have disrupted a particulate hnRNP structure, which is superimposed in vivo on the splicing complexes but is disrupted by the 
chromatin-spreading conditions /see Fig. 6 in Osheim et al. 1985). We have found that isolated HeLa hnRNP particles dissociate in the spreading solution (L. Mesner and A. Beyer, unpubl.).

\section{Relationship of the observed structures to structures characterized in in vitro splicing systems}

We are able to speculate on the nature and composition of the various structures observed because they are very much as predicted from in vitro splicing systems. The first observable structure related to splicing is a small particle $(\sim 10 \mathrm{~nm})$ or irregularity at the $5^{\prime}$ splice site, which is seen in $\sim 50 \%$ of possible cases before the $3^{\prime}$ splice site is synthesized (Figs. 1, 2, and 5). The most obvious candidate for this particle is U1 snRNP, which associates with the $5^{\prime}$ consensus sequence very readily in the nuclear extract in vitro (Mount et al. 1983; Black et al. 1985). The next structure observed in EM spreads is a $\sim 25-\mathrm{nm}$ particle at the $3^{\prime}$ splice junction region. (Recall that we cannot distinguish the branch site from the $3^{\prime}$ splice site because each particle covers at least 100 nucleotides of RNA.) Our observation of the $3^{\prime}$ splice region particle as the first stable particle is entirely consistent with previous findings from in vitro studies that the $3^{\prime}$ region is essential for initiating spliceosome assembly (Frendewey and Keller 1985; Ruskin and Green 1985; Cheng and Abelson 1987; Krämer 1987). This particle can be seen in the earliest cases within $\sim 13 \mathrm{sec}$ of synthesis of the $3^{\prime}$ splice site and yet, based on its size, probably represents the deposition of more than one component at that site. It is presumably a complex of protein factor(s) (Gerke and Steitz 1986; Tazi et al. 1986; Ruskin et al. 1988), U2 snRNP (Black et al. 1985; Parker et al. 1987), and perhaps one or two more snRNPs from among U4, U5, or U6 (Grabowski and Sharp, 1986), with U5 being the most likely candidate (Chabot et al. 1985). The observation that it adopts its largest configuration as soon as, or very soon after, it is detected is consistent with in vitro results, indicating that U4, U5, and U6 snRNPs associate simultaneously in the spliceosome (Konarska and Sharp 1987), immediately following U2 snRNP binding (Bindereif and Green 1987). We presume that U1 snRNP is at the 5' splice site and that U4, U5, and U6 do not all segregate to one of the two splice sites. This is based simply on the observation that the two splice junction particles are about the same size $(25 \mathrm{~nm})$, which is appropriate for two to three snRNPs plus a few additional protein factors.

There is a stabilization of the $5^{\prime}$ splice site-Ul snRNP interaction in vitro, which is dependent on snRNP interactions with the $3^{\prime}$ end of the intron and is represented by a larger RNase T1-protected RNA fragment (Chabot and Steitz 1987) or an RNAse A-protected fragment (Krämer 1987) on $5^{\prime}$ splice sites. The ultrastructural correlate to this stabilization is probably the $25-\mathrm{nm}$ particle that forms at the $5^{\prime}$ splice site within $\sim 40 \sec$ of $3^{\prime}$ splice site particle formation (Table 1). Based on the dependence of the $5^{\prime}$ splice site particle on $3^{\prime}$ splice site synthesis (Figs. 1-3), we conclude that the $5^{\prime}$ - and $3^{\prime}$-splice site particles observed on dispersed transcripts are prob- ably in contact in the cell. Additional components may assemble at the $5^{\prime}$ splice site concurrently with $3^{\prime}$ splice site particle formation (Bindereif and Green 1987; Konarska and Sharp 1987; Lamond et al. 1987; Zillmann et al. 1987); but may be unstable to our spreading conditions until Ul snRNP 'stabilization' because Ul snRNP is the only snRNP with appreciable contacts on the $5^{\prime}$ splice site RNA (Bindereif and Green 1987).

The conversion of a linear transcript to a looped structure with a single large particle at its base, which is stable to EM spreading conditions, may represent covalent lariat formation between the $5^{\prime}$ end of the intron and the branch site A residue. Loop formation is followed within a minute by loop removal (Table 1). The bulk of the spliceosome particle is removed from the nascent transcript (i.e., the spliced exons) upon intron removal (Figs. 1, 2D, 5D, 6) (cf. Konarska and Sharp 1987).

\section{Kinetics of splice site selection and splicing in vivo}

It has been well established in studies of specific RNA processing pathways that different introns are removed with different kinetics and that splicing reactions are typically complete within 3-30 min (Darnell 1982). The textbook version of RNA processing states that polyadenylation precedes splicing because this has been demonstrated directly for a number of abundant mRNAs and is assumed for others in which polyadenylated precursors, larger than the mRNAs, can be detected (for review, see Nevins 1983). It is known that polyadenylation is not a prerequisite to splicing (Zeevi et al. 1981; Green et al. 1983), that splicing can precede polyadenylation in at least one case (Keohavong et al. 1982; Mariman et al. 1983), and in another case, the commitment to certain splice sites precedes both polyadenylation and splicing, consistent with cotranscriptional splice site selection (Leff et al. 1987). In a comparative study of splicing of pre-mRNAs with mutant splice junctions in vivo and in vitro, Aebi et al. (1986) proposed the 'firstcome-first-served' principle of splice site selection, stating that the order of synthesis of the RNA in vivo favored the formation of committed presplicing complexes on the introns as they were synthesized. Other comparative studies of splicing in vivo and in vitro can be explained by the coupling of transcription and splice site selection (Kedes and Steitz 1987; Lowery and van Ness 1987). Thus, our observation of splice site selection and splicing on nascent transcripts (prior to transcript release from the template and thus presumably prior to polyadenylation), is surprising only in the extent to which it is observed $185 \%$ of transcription units display RNP particles, $46 \%$ display loop formation, and at least $14 \%$ display loop removal). There may be a higher percentage of cotranscriptional splicing in these rapidly growing embryos and also an increased likelihood of seeing very long developmental loci (Scott 1987). In general, the longer the gene, the greater chance there is of seeing intron removal on nascent transcripts, given the 3-min requirement for this class of early splicing events, in which the only rate-limiting step may be the 
synthesis of the $3^{\prime}$ splice site. One interpretation of our results is that a second rate-limiting step operates after partial spliceosome formation in some cases (cf. Chabot and Steitz 1987), because a large fraction of the genes $(38 \%)$ display $25-\mathrm{nm}$ particles with no loop formation. If these $25 \mathrm{~nm}$ particles represent spliceosome intermediates, our results indicate that the cotranscriptional formation of 'committed presplicing complexes' may be very common, whereas the actual splicing event is much less common on nascent transcripts. Evidence that the $25-\mathrm{nm}$ particles represent a commitment to a splicing pathway comes from observation of two cases of exon skipping in which the skipped splice junctions do not display RNP particles on those transcripts where they are skipped (Fig. 6; A. Beyer, unpubl.). This observation also suggests that the $25-\mathrm{nm}$ particles may be a structural component participating in, or recognized by, a scanning mechanism (Sharp 1981) that probably operates to some degree in splice site pairing, although not in any simply explained fashion as yet (for discussion, see Green 1986; Breitbart et al. 1987).

The observation of cotranscriptional spliceosome assembly is important because of its implications concerning appropriate splice site pairing in transcripts with multiple introns and supports possible roles for splice site proximity (Reed and Maniatis 1986) and order of transcription (Aebi et al. 1986) in the process. Although there are cases in which the first-come-first-served principle does not apply in vivo (e.g., Mitchell et al. 1986; Marvit et al. 1987) and where in vitro splicing of multiple introns proceeds accurately on a presynthesized transcript (Lang and Spritz 1987), it is probably an important factor in some situations nonetheless, as proposed most convincingly by Aebi et al. (1986). Our observations support their explanation for the differences observed between splice site selection in vivo and in vitro and are consistent with a modified first-come-firstserved model, which accommodates different rates of splice site selection, as discussed by Lang and Spritz (1987). Such a mechanism would tend to suppress exon skipping but would be consistent with non- $5^{\prime} \rightarrow 3^{\prime}$ directional orders of intron excision and alternative splicing possibilities. It is quite possible that some introns are not apparent using our approach because splice site selection is delayed until after polyadenylation. The resolution of such questions requires the visualization of specific genes in chromatin spreads, which we are pursuing using plasmid vector introduction into Drosophila embryos.

\section{Methods}

Details of the chromatin spreading procedure (Miller and Beatty 1969) for Drosophila embryos have been described previously (Beyer et al. 1981). Briefly, 2- to 4-hr-old embryos were manually dechorionated, transferred to a drop of spreading solution (either $\mathrm{H}_{2} \mathrm{O}$ at $\mathrm{pH} 9$ or $0.05 \%$ Joy detergent at $\mathrm{pH} 8.5-9$ ), and macerated with forceps. The chromatin was allowed to disperse for 5-15 $\mathrm{min}$, after which it was fixed with formalin and centrifuged onto an EM grid through a $0.1 \mathrm{M}$ sucrose cushion. Grids were stained with phosphotungstic acid and uranyl acetate and then rotary shadow cast with platinum. RNP particle size measurements were done on metal-shadowed preparations and thus reflect relative, rather than absolute, sizes.

The following procedures have also been described: classification of transcription units as nucleolar or nonnucleolar (McKnight and Miller 1979), contour length measurement, linear regression analysis, and RNP fibril map construction (see also legend to Fig. 1) (Beyer et al. 1980, 1981).

The conversion of contour length measurements (micrometers) to molecular size (kilobase pairs) is based on the assumption that DNA contraction is inversely proportional to RNP fibril frequency and varies on a linear continuum between $3.3 \mathrm{~kb} / \mu \mathrm{m}$ (the contraction ratio of the fully transcribed $\mathrm{rDNA}$ and chorion genes in these preparations) and $4.8 \mathrm{~kb} / \mu \mathrm{m}$ (the contraction ratio of nucleosomal DNA in these preparations) (McKnight and Miller 1979; Osheim et al. 1986). Examination of the genes with a low transcript density (Fig. 2, 5, and 6) reveals that nucleosomes are indeed present between RNA polymerase molecules.

\section{Acknowledgments}

We especially thank Dr. Oscar L. Miller, Jr., for his initial support of, and continued interest in, this research. This work was supported by grants from the American Cancer Society (NP-493A) and the National Science Foundation (DMB-8702500) to A.L.B. Y.N.O. was supported by National Institutes of Health Training Grant 5T32CA09109-11. A.L.B. is the recipient of an American Cancer Society Faculty Research Award.

\section{References}

Aebi, M., H. Hornig, R.A. Padgett, J. Reiser, and C. Weissman. 1986. Sequence requirements for splicing of higher eukaryotic nuclear pre-mRNA. Cell 47: 555-565.

Bernstein, S.I., C.I. Hansen, K.D. Becker, D.R. Wassenberg, E.S. Roche, J.J. Donady, and C.P. Emerson. 1986. Alternative RNA splicing generates transcripts encoding a thorax-specific isoform of Drosophila melanogaster myosin heavy chain. Mol. Cell. Biol. 6: 2511-2519.

Beyer, A. 1983. Ultrastructural analysis of the ribonucleoprotein structure of nascent hnRNA. Mol. Biol. Rep. 9: 49-58.

Beyer, A.L., A.H. Bouton, and O.L. Miller, Jr. 1981. Correlation of hnRNP structure and nascent transcript cleavage. Cell 26: $155-165$.

Beyer, A.L., O.L. Miller, Jr., and S.L. McKnight. 1980. Ribonucleoprotein structure in nascent hnRNA is nonrandom and sequence-dependent. Cell 20: 75-84.

Beyer, A.L., M.E. Christensen, B.W. Walker, and W.M. LeStourgeon. 1977. Identification and characterization of the packaging proteins of core $40 \mathrm{~S}$ hnRNP particles. Cell 11: 127138.

Bindereif, A. and M.R. Green. 1987. An ordered pathway of snRNP binding during mammalian pre-mRNA splicing complex assembly. EMBO I. 6: 2415-2424.

Black, D.L., B. Chabot, and J.A. Steitz. 1985. U2 as well as U1 small nuclear ribonucleoproteins are involved in premessenger RNA splicing. Cell 42: 737-750.

Bozzoni, I., F. Annesi, E. Beccari, P. Fragapane, P. PierandreiAmaldi, and F. Amaldi. 1984. Splicing of Xenopus laevis ribosomal protein RNAs is inhibited in vivo by antisera to ribonucleoproteins containing small nuclear RNA. $/$. Mol. Biol. 180: 1173-1178.

Breitbart, R.E., A. Andreadis, and B. Nadal-Ginard. 1987. Alternative splicing: A ubiquitous mechanism for the generation 
of multiple protein isoforms from single genes. Annu. Rev. Biochem. 56: 467-495.

Brody, E. and J. Abelson. 1985. The 'spliceosome': Yeast premessenger RNA associates with a $40 \mathrm{~S}$ complex in a splicing-dependent reaction. Science 228: 963-967.

Chabot, B. and J.A. Steitz. 1987. Multiple interactions between the splicing substrate and small nuclear ribonucleoproteins in spliceosomes. Mol. Cell. Biol. 7: 281-293.

Chabot, B., D.L. Black, D.M. LeMaster, and J.A. Steitz. 1985. The $3^{\prime}$ splice site in premessenger RNA is recognized by a small nuclear ribonucleoprotein. Science 230: 1344-1349.

Cheng, S.-C. and J. Abelson. 1987. Spliceosome assembly in yeast. Genes Dev. 1: 1014-1027.

Choi, Y.D., P.J. Grabowski, P.A. Sharp, and G. Dreyfuss. 1986. Heterogeneous nuclear ribonucleoproteins: Role in RNA splicing. Science 231: 1534-1539.

Christofori, G., D. Frendewey, and W. Keller. 1987. Two spliceosomes can form simultaneously and independently on synthetic double-intron messenger RNA precursors. EMBO J. 6: 1747-1755.

Chung, S.Y. and J. Wooley. 1986. Set of novel, conserved proteins fold pre-messenger RNA into ribonucleosomes. Proteins: Structure, Function, Genet. 1: 195-210.

Cobianchi, F., D.N. SenGupta, B.Z. Zmudzka, and S.H. Wilson. 1986. Structure of rodent helix-destabilizing protein revealed by cDNA cloning. J. Biol. Chem. 261: 3536-3543.

Conway, G., J. Wooley, T. Bibring, and W. M. LeStourgeon. 1988. Ribonucleoproteins package 700 nucleotides of premRNA into a repeating array of regular particles. Mol. Cell. Biol. (in press).

Darnell, J.E., Jr. 1982. Variety in the level of gene control in eukaryotic cells. Nature 297: 365-371.

Domdey, H., B. Appostel, R.-J. Lin, A. Newman, E. Brody, and J. Abelson. 1984. Lariat structures are in vivo intermediates in yeast pre-mRNA splicing. Cell 39: 611-621.

Dreyfuss, G. 1986. Structure and function of nuclear and cytoplasmic RNP particles. Annu. Rev. Cell. Biol. 2: 459-498.

Fakan, S., G. Leser, and T.E. Martin. 1986. Immunoelectron microscope visualization of nuclear ribonucleoprotein antigens within spread transcription complexes. I. Cell Biol. 103: $1153-1157$.

Falkenthal, S., V.P. Parker, and N. Davidson. 1985. Developmental variations in the splicing pattern of transcripts from the Drosophila gene encoding myosin alkali light chain results in different carboxylterminal amino acid sequences. Proc. Natl. Acad. Sci. 82: 449-453.

Fradin, A., R. Jove, C. Hemenway, H.D. Keiser, J.C. Manley, and C. Prives. 1984. Splicing pathways of SV40 mRNAs in $X$. laevis oocytes differ in their requirements for snRNPs. Cell 37: 927-936.

Frendewey, D. and W. Keller. 1985. The stepwise assembly of a pre-mRNA splicing complex requires U-snRNPs and specific intron sequences. Cell 42: 355-367.

Gerke, V. and J.A. Steitz. 1986. A protein associated with small nuclear ribonucleoprotein particles recognizes the $3^{\prime}$ splice site of premessenger RNA. Cell 47: 973-984.

Grabowski, P.J. and P.A. Sharp. 1986. Affinity chromatography of splicing complexes: U2, U5, and U4 + U6 small nuclear ribonucleoprotein particles in the spliceosome. Science 223: $1294-1299$.

Green, M.R. 1986. Pre-mRNA splicing. Annu. Rev. Genet. 20: $671-708$.

Green, M.R., T. Maniatis, and D.A. Melton. 1983. Human betaglobin pre-mRNA synthesized in vitro is accurately spliced in Xenopus oocyte nuclei. Cell 32: 681-694.

Hager, E.J. 1987. Ultrastructural aspects of gene expression in
Drosophila melanogaster polytene chromatin. Ph.D. dissertation. University of Virginia, Charlottesville, Virginia.

Kafatos, F.C. 1972. The cocoonase zymogen cells of silk moths: A model of terminal differentiation for specific protein synthesis. Curr. Topics Dev. Biol. 1: 125-191.

Kedes, D.H. and J.A. Steitz. 1987. Accurate 5' splice-site selection in mouse kappa immunoglobulin light chain premessenger RNA is not cell-type-specific. Proc. Natl. Acad. Sci. 84: 7928-7932.

Keohavong, P., R. Gattoni, P. Schmitt, and J. Stévenin. 1986. The different intron 2 species excised in vivo from the E2A pre-mRNA of adenovirus-2: An approach to analyze alternative splicing. Nucleic Acids Res. 14: 5207-5227.

Keohavong, P., R. Gattoni, J.M. LeMoullec, M. Jacob, and J. Stévenin. 1982. The orderly splicing of the adenovirus- 2 major late transcript. Nucleic Acids Res. 10: 1215-1229.

King, C. and J. Piatigorsky. 1984. Alternative splicing of alpha A-crystallin RNA. J. Biol. Chem. 259: 1822-1826.

Konarska, M.M. and P.A. Sharp. 1986. Electrophoretic separation of complexes involved in the splicing of precursors to mRNAs. Cell 46: 845-855.

. 1987. Interactions between small nuclear ribonucleoprotein particles in formation of spliceosomes. Cell 49: 763-774.

Konarska, M.M., P.J. Grabowski, R.A. Padgett, and P.A. Sharp. 1985. Characterization of the branch site in lariat RNAs produced by splicing mRNA precursors. Nature 313: 552557.

Krämer, A. 1987. Analysis of RNase-A-resistant regions of adenovirus 2 major late precursor-mRNA in splicing extracts reveals an ordered interaction of nuclear components with the substrate RNA. J. Mol. Biol. 196: 559-573.

Kumar, A., K.R. Williams, and W. Szer. 1986. Purification and domain structure of core hnRNP proteins $A 1$ and $A 2$ and their relationship to single-stranded DNA-binding proteins. I. Biol. Chem. 261: 11266-11273.

Lahiri, D.K. and J.O. Thomas. 1986. A cDNA clone of the hnRNP C proteins and its homology with the singlestranded DNA binding protein UP2. Nucleic Acids Res. 14: $4077-4094$

Lamond, A.I., M.M. Konarska, and P.A. Sharp. 1987. A mutational analysis of spliceosome assembly: Evidence for splice site collaboration during spliceosome formation. Genes Dev. 1: 532-543.

Lang, K.M. and R.A. Spritz. 1987. In vitro splicing pathways of pre-mRNAs containing multiple intervening sequences. Mol. Cell Biol. 7: 3428-3437.

Leff, S.E., R.M. Evans, and M.G. Rosenfeld. 1987. Splice commitment dictates neuron-specific alternative RNA processing in calcitonin/CGRP gene expression. Cell 48: 517524.

Lothstein, L., H.P. Arenstorf, S. Chung, B.W. Walker, I.C. Wooley, and W.M. LeStourgeon. 1985. General organization of protein in HeLa $40 \mathrm{~S}$ nuclear ribonucleoprotein particles. J. Cell Biol. 100: 1570-1581.

Lowery, D.E. and B.G. Van Ness. 1987. In vitro splicing of kappa immunoglobulin precursor mRNA. Mol. Cell Biol. 7: $1346-1351$.

Maniatis, T. and R. Reed. 1987. The role of small nuclear ribonucleoprotein particles in pre-mRNA splicing. Nature 325: 673-678.

Mann, R.S. 1986. Measurement of transcription elongation rates in Drosophila melanogaster by electron microscopy. M.S. dissertation, University of Virginia, Charlottesville.

Mariman, E.C.M., R.J. van Beek-Reinders, and W.J. van Venrooij. 1983. Alternative splicing pathways exist in the 
formation of adenoviral late messenger RNAs. J. Mol. Biol. 163: $239-256$.

Marvit, J., A.G. DiLella, K. Brayton, F.D. Ledley, K.J.H. Robson, and S.L.C. Woo. 1987. GT to AT transition at a splice donor site causes skipping of the preceding exon in Phenylketonuria. Nucleic Acids Res. 15: 5613-5629.

McKnight, S.L. and O.L. Miller, Jr. 1979. Post-replicative nonribosomal transcription units in $D$. melanogaster embryos. Cell 17: 551-563.

Miller, O.L., Jr. and B.R. Beatty. 1969. Visualization of nucleolar genes. Science 164: 955-957.

Mitchell, P.J., G. Urlaub, and L. Chasin. 1986. Spontaneous splicing mutations at the dihydrofolate reductase locus in Chinese hamster ovary cells. Mol. Cell. Biol. 6: 1926-1935.

Mount, S.M., I. Peterson, M. Hinterberger, A. Karmas, and J.A. Steitz. 1983. The U1 small nuclear RNA-protein complex selectively binds a $5^{\prime}$ splice site in vitro. Cell 33: 509-518.

Nevins, J.R. 1983. The pathway of eukaryotic mRNA formation. Annu. Rev. Biochem. 52: 441-466.

Nowak, L., D.K. Marvil, J.O. Thomas, M. Boublik, and W. Szer. 1980. A single-stranded nucleic acid-binding protein from Artemia salina. II. Interaction with nucleic acids. J. Biol. Chem. 255: 6473-6478.

Osheim, Y.N., O.L., Miller, Jr., and A.L. Beyer. 1985. RNP particles at splice junction sequences on Drosophila chorion transcripts. Cell 43: 143-151.

- 1986. Two Drosophila chorion genes terminate transcription in discrete regions near their poly(A) sites. $E M B O$ J. 5: 3591-3596.

Padgett, R.A., P.J. Grabowski, M.M. Konarska, S. Seiler, and P.A. Sharp. 1986. Splicing of messenger RNA precursors. Annu. Rev. Biochem. 55: 1119-1150.

Parker, R., P.G. Siliciano, and C. Guthrie. 1987. Recognition of the TACTAAC box during mRNA splicing in yeast involves base-paring to the U2-like snRNA. Cell 49: 229-239.

Patton, J.R. and C.B. Chae. 1985. Specific regions of the intervening sequence of beta-globin RNA are resistant to nuclease in 50S heterogeneous nuclear RNA-protein complexes. Proc. Natl. Acad. Sci. 82: 8414-8418.

Pullman, J.M. and T.E. Martin. 1983. Reconstitution of nucleoprotein complexes with mammalian heterogeneous nuclear ribonucleoprotein (hnRNP) core proteins. I. Cell Biol. 97: 99-111.

Reed, R. and T. Maniatis. 1985. Intron sequences involved in lariat formation during pre-mRNA splicing. Cell 41: 95105.

1986. A role for exon sequences and splice-site proximity in splice-site selection. Cell 46: 681-690.

Riva, S., C. Morandi, P. Tsoulfas, M. Pandolfo, G. Biamonti, B. Merrill, K.R. Williams, G. Multhaup, K. Beyreuther, H. Werr, B. Henrich, and K.P. Schäfer. 1986. Mammalian single-stranded DNA binding protein UP1 is derived from the hnRNP core protein Al. EMBO I. 5: 2267-2273.

Rodriguez, J.R., C.W. Pikielny, and M. Rosbash. 1984. In vivo characterization of yeast mRNA processing intermediates. Cell 39: 603-610.

Ruskin, B. and M.R. Green. 1985. Specific and stable intronfactor interactions are established early during in vitro mRNA splicing. Cell 43: 131-142.

Ruskin, B., J. Greene, and M.R. Green. 1985. Cryptic branch point activation allows accurate in vitro splicing of human beta-globin intron mutants. Cell 41: 833-844.

Ruskin, B., P.D. Zamore, and M.R. Green. 1988. A factor, $\mathrm{U} 2 \mathrm{AF}$, is required for $\mathrm{U} 2$ snRNP binding and splicing complex assembly. Cell 52: 207-219.

Sass, H. and T. Pederson. 1984. Transcription-dependent local- ization of $\mathrm{U} 1$ and $\mathrm{U} 2$ small nuclear ribonucleoproteins at major sites of gene activity in polytene chromosomes. $I$. Mol. Biol. 180: 911-926.

Scott, M. 1987. Complex loci of Drosophila. Annu. Rev. Biochem. 56: 195-227.

Sharp, P.A. 1981. Speculations on RNA splicing. Cell 23: 643646.

Sierakowska, H., W. Szer, P.J. Furdon, and R. Kole. 1986. Antibodies to hnRNP proteins inhibit in vitro splicing of human beta globin pre-mRNA. Nucleic Acids Res. 14: 5241-5254.

Skoglund, V., K. Anderson, B. Bjorkroth, M. Lamb, and B. Daneholt. 1983. Visualization of the formation and transport of a specific hnRNP particle. Cell 34: 847-855.

Solnick, D. and S.I. Lee. 1987. Amount of RNA secondary structure required to induce an alternative splice. Mol. Cell Biol. 7: 3194-3198.

Spector, D.L., W.H. Schrier, and H. Busch. 1983. Immunoelectron microscopic localization of snRNPs. Biol. Cell 49: $1-10$.

Steitz, J.A., D.L. Black, V. Gerke, K.A. Parker, A. Kr̈amer, D. Frendewey, and W. Keller. 1987. Functions of the abundant U-snRNPs. In Structure and functions of small nuclear ribonucleoprotein particles (ed. M.L. Birnstiel), pp. 115-154. Springer-Verlag, Berlin, Heidelberg, New York.

Tazi, J., C. Alibert, J. Tensamani, I. Reveillaud, G. Cathala, C. Brunel, and P. Jeanteur. 1986. A protein that specifically recognizes the $3^{\prime}$ splice site of mammalian pre-mRNA introns is associated with a small nuclear ribonucleoprotein. Cell 47: 755-766.

Thomas, J.O., Raziuddin, A. Sobota, M. Boublik, and W. Szer. 1981. An RNA helix-destabilizing protein is a major component of Artemia salina nuclear ribonucleoproteins. Proc. Natl. Acad. Sci. 78: 2888-2892.

Wilk, H., G. Angeli, and K.P. Schafer. 1983. In vitro reconstitution of $35 \mathrm{~S}$ ribonucleoprotein complexes. Biochemistry 22: $4592-4600$.

Yost, H.J. and S. Lindquist. 1986. RNA splicing is interrupted by heat shock and is rescued by heat shock protein synthesis. Cell 45: 185-193.

Zeevi, M., J.R. Nevins, and J.E. Darnell. 1981. Nuclear RNA is spliced in the absence of poly(A) addition. Cell 26: 39-46.

Zeitlin, S. and A. Efstratiadis. 1984. In vivo splicing products of the rabbit beta-globin pre-mRNA. Cell 39: 589-602.

Zhuang, Y., and A.M. Weiner. 1986. A compensatory base change in U1 snRNA suppresses a $5^{\prime}$ splice site mutation. Cell 46: 827-835.

Zillmann, M., S.D. Rose, and S.M. Berget. 1987. U1 small nuclear ribonucleoproteins are required early during spliceosome assembly. Mol. Cell Biol. 7: 2877-2883. 


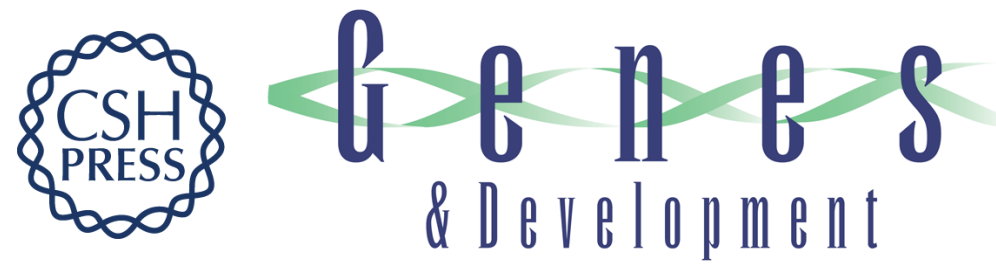

\section{Splice site selection, rate of splicing, and alternative splicing on nascent transcripts.}

A L Beyer and Y N Osheim

Genes Dev. 1988, 2:

Access the most recent version at doi:10.1101/gad.2.6.754

References This article cites 82 articles, 24 of which can be accessed free at:

http://genesdev.cshlp.org/content/2/6/754.full.html\#ref-list-1

License

Email Alerting Receive free email alerts when new articles cite this article - sign up in the box at the top Service right corner of the article or click here.

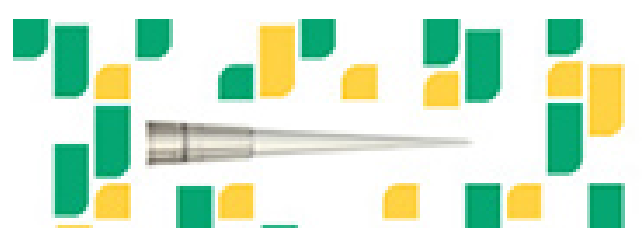

Focused on your science. 